\title{
Enhancing Creative Thinking In A Case-Based MBA Course
}

Cynthia M. Newman, (E-mail: cnewman@rider.edu), Rider University

\begin{abstract}
Improving the critical thinking ability of students is a learning outcome of many undergraduate and graduate courses. While case-based courses encourage higher order critical thinking, students still often become rote in the application of concepts and theories to problem-solving situations. This paper presents an example of a graduate marketing MBA course that was revised by integrating the creative problem solving process with the traditional case analysis process in order to enhance student critical thinking and problem solving skills.
\end{abstract}

\subsection{Introduction}

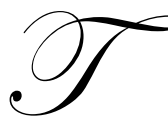

he focus of this paper will be on the revision of a graduate marketing course in an effort to improve students' ability to generate and develop alternative solutions that move beyond generic application of basic strategy typology and that challenge the applicability of principles/theoretical concepts to practical decision making contexts. The purpose of the graduate marketing course entitled Marketing Analysis and Decision Making is to provide students with analytical and problem solving skills, in the context of marketing. This was traditionally done through the analysis of cases that describe actual marketing problems faced by a variety of organizations. In every case, students needed to develop a strategy that was consistent with the underlying factors existing in the situation presented and that considered the implications of that strategy for the organization and its environment.

However, during the case analysis stage of alternative strategy development, students tended to present as alternatives the basic definitions of various strategy types (e.g., market penetration, market development, diversification) as opposed to developing alternatives that reflected the complexities and peculiarities of the decision making context and influencing forces. There was very little attempt to generate alternatives that were hybrids of multiple generic strategies. The students tended to approach marketing decision making as they would a financial analysis: with the goal of identifying the one best alternative. While marketing decision making certainly considers quantitative analysis in the strategy development and evaluation process, it also involves a fair amount of professional judgment based on qualitative impressions. In response to most marketing decision issues there are several legitimate strategic alternatives, not just one "correct" option. Students tended to miss this point, or, at least, to refrain from articulating options that were particularly creative. This occurrence was of particular concern since educators and corporate leaders appear to agree that two of the most critical skills currently needed in business are problem solving and creativity (Driver, 2001; Goldsmith, 2001; Snyder, 2003).

A process that addresses both of these skills is the creative problem solving process (CPS) which encourages the use of both divergent and convergent thinking to solve problems or "reach goals when the means to do so are not readily apparent" (Brophy, 2000-2001, p. 439). A simple explanation of the two modes of thinking involved in this process is as follows: "divergent thought from a single starting point generates varied ideas, whereas convergent thought starting from multiple points seeks one most true or useful conclusion" (Brophy, 2000-2001, p. 439). Creativity finds its place in this problem solving process largely as a result of research first conducted by Guilford (1950) that linked divergent thinking to creative thought. Baer (1997) explains that the creative problem solving process employs the powerful divergent thinking tool of brainstorming during each of six steps to encourage divergent thinking, which results in the generation of numerous, varied and creative ideas. Following the exercise of 
divergent thinking, evaluative (or convergent) thinking is then applied to choose the "best" idea given various constraints and decision criteria.

The instructor believed that creative problem solving (CPS) strategies would be appropriate means of encouraging students to engage in thought that would result in the generation of more practically appropriate alternatives to complex, real-world marketing issues during case analyses and, ultimately, during strategic decision making in their work settings. As an added benefit, creative thinking and creative problem solving also are more likely to lead to higher levels of critical thinking, which is one of the primary learning outcomes for the course. Following is a discussion of the process and results of integrating creative problem solving into the graduate marketing course.

\subsection{Process of Integrating CPS into the Course}

With the exception of the first step, the six steps of CPS correspond well to the steps of the traditional case analysis process that had been used in the MBA course (see Table 1). This correspondence provided the instructor with confidence that an integration of CPS into the course could be accomplished in a seemless manner. In essence, students would be given the case analysis process as a framework for analyzing and addressing an organization's marketing problems/issues and would be given the CPS process as a tool for accomplishing the analysis. For each step of the case analysis process, students would engage in divergent and evaluative thinking.

TABLE 1: Correspondence Between CPS and Case Analysis Process

\begin{tabular}{|l|l|}
\hline CPS STEPS & CASES ANALYSIS STEPS \\
\hline & \\
\hline Mess-finding & \\
\hline Data-finding & Environmental \& Internal (SWOT)Analysis \\
\hline Problem-finding & Problem/Issue Identification \\
\hline Idea-finding & Alternative Solution Identification \\
\hline Solution-finding & Strategy Recommendation \\
\hline Action-planning & Implementation \& Evaluation \\
\hline
\end{tabular}

As a starting point in the process of restructuring the course, the instructor used the CPS process. There were three primary outcomes from this application of CPS. First, the instructor realized that in order for students to learn and then apply CPS, much class time would need to be allocated to this process. Second, while it appeared to be relatively easy to merge CPS with the traditional case analysis process, there was a need to motivate students to take the case analysis process seriously. Third, encouraging student creativity through CPS required a change in how student coursework would be assessed.

To address the first outcome concerning a need to free up more class time for CPS, the instructor turned to technology. First, since the course was already being supported by a Blackboard site, the instructor decided to place on the site a section dedicated to the creative problem solving process; this folder contains a description of CPS, bibliographic references to CPS articles and books, an overview of the brainstorming process, and descriptions of divergent and evaluative thinking. Students could access this site throughout the semester to review the CPS process and reinforce class discussions and exercises. Second, technology also was used to make more class time available for student application of CPS by posting PowerPoint ${ }^{\circledR}$ presentations containing reviews of marketing topics that would otherwise have been reviewed in class. Even though students are expected to be familiar with basic marketing concepts prior to enrolling in the course, many students require a review of these concepts before they are ready to apply the concepts to case scenarios. Instead of conducting full reviews of concepts in class through lectures or active learning experiences, the revised course required student review of these concepts through the Blackboard site. Class time would be used to address questions and comments on the material reviewed independently by the students. 
As for the second outcome of motivating students to take the case analysis process seriously, the instructor incorporated living marketing cases into the course through the use of clients. Collaborative projects between higher education and industry have met with success in developing problem-solving, communication, and teamwork skills (Charp, 1998; Faber, 1999; O'Brien and Hart, 1999; Thomas and Busby, 2003). In addition to enhancing these skills, the instructor also believed that the industry interaction would enhance student commitment of time and mental focus to the analysis process. The client, for the first semester in which the revised course was offered, was a District Office of the EEOC. This client was having difficulty meeting attendance goals for training assistance programs targeted to small and medium sized businesses in a four-state region. The client for the second semester in which the course was offered was a title/closing company. This client, who did not have a formal marketing plan, wanted to increase market presence with the specific goal of sustaining a $20 \%$ annual growth rate over the next five years. Student teams met with the clients throughout the semesters in person as well as communicated through email. At the end of each 13 session semester, teams delivered formal presentations of their recommended strategies to the clients. Each team also provided the clients with detailed written plans that included the results of the environmental analysis, descriptions and justifications of the recommended strategies, implementation schedules, and evaluation plans.

Finally, the third outcome concerning assessment of student application of CPS was addressed in the following manner. The scoring rubrics for assignments involving case analysis were revised to include a section that addresses whether CPS has been employed. This section of the rubric has only two levels of evaluation: a "full credit" point for students who applied the CPS process, as evidenced through a series of lists noting the results of divergent and evaluative thinking for each step of the process, and a "no credit" point for students who did not apply the CPS process. The strongest extrinsic motivation for applying the CPS process is that this section of the rubric accounts for $10 \%$ of the total assignment grade; therefore, it is not possible to receive an A on an assignment that requires the use of CPS if evidence is not provided that CPS was used. Given the instructor's desire to encourage creativity, it would be counterproductive, not to mention extremely difficult, to identify criteria for different levels of creativity.

\subsection{Results of the Integration}

From the perspective of students, clients and the instructor over the span of two semesters, the integration is a success. By serving as consultants to real-world organizations with immediate marketing issues in need of resolution, student teams assigned a high priority and urgency to the analysis process and resulting recommendations. The client representatives were pleased with the analysis and recommendations made and intended to implement several of the strategies. From an academic perspective, the instructor found that student teams performed at a much higher level than in previous administrations of the course. Environmental analyses were detailed and thorough; strategy alternatives were varied, creative and highly relevant to the identified marketing problems/issues; and recommendations were viable. In addition, implementation guidelines included detailed cost-benefit analyses as well as comparative analyses of in-house versus out-sourced suppliers of requisite services.

Finally, both informal and formal student course assessment following the integration of CPS and living marketing cases provided evidence that the integration was successful. On an informal level, the instructor received comments from different students each week that showed they were thinking at a higher level than they were used to in their coursework. One student said, "My brain hurts by the end of the night." On a more formal level, mean ratings for the course evaluation items of "stimulation of thinking" and "helpfulness of outside assignments" were more than a half a point higher (on a five point rating scale) at the end of each of the semesters following the integration than they had been after all previous administrations of the course by the same instructor, using the same text.

A resulting challenge of this integration for the instructor became balancing the academic content of the course with the application of concepts/processes through the living marketing case. The time commitment required for the project appeared to pull students away from the text and paper cases in which marketing concepts and marketing management issues were examined. As a result, the instructor needed to include in the course both 
formal and informal means of ensuring that students were reading and considering the theoretical and conceptual aspects of the course content. The most formal means employed were unannounced, short essay tests on assigned readings and individually written analyses of text cases. Informal means included class discussions of current articles from The Wall Street Journal and reflection journal entries in which students linked text material to work experiences.

\subsection{Conclusion}

The CPS process, in combination with the collaborative industry consultation project, did enhance student critical thinking and resulted in the generation of creative marketing strategies that had real-world applicability. In addition, an unanticipated but highly valued outcome of this integration was the realization on the part of many students that learning the strategic marketing decision making process not only satisfied a requirement as they pursue a degree to improve their chances of upward career mobility, but also provided them with skills that are transferable to a wide range of academic, business and personal situations.

\subsection{References}

1. Baer, John. (1997). Creative Teachers, Creative Students. Boston: Allyn and Bacon.

2. Brophy, Dennis R. (2000-2001). "Comparing the attributes, activities, and performance of divergent, convergent, and combination thinkers," Creativity Research Journal, 13(3 \& 4), 439-455.

3. $\quad$ Charp, Sylvia. (1998). "Industry/education partnerships," THE Journal, 26(3), 6.

4. Driver, Michaela. (2001). "Fostering Creativity in business education: Developing creative classroom environments to provide students with critical workplace competencies," Journal of Education for Business, 77(1), 28-33.

5. Faber, Marsh. (1999). "Industry/education collaborations produce long-term job survivors," Tech Directions, 58(10), 29.

6. $\quad$ Goldsmith, Barton. (2001). "Innovative Problem Solving," AFP Exchange, 21(4), 78-79.

7. $\quad$ Guilford. Joy P. (1950). "Creativity," American Psychologist, 5, 444-454.

8. O'Brien, Elaine M. and Hart, Susan J. (1999). "Action learning: The link between academia and industry?" Educational Research, 41(1), 77-89.

9. Snyder, Kimberlee D. (2003). "Ropes, poles, and space: Active learning in business education," Active Learning in Higher Education, 4(2), 159-167.

10. Thomas, Sarah, and Busby, Susan. (2003). "Do industry collaborative projects enhance students' learning?" Education and Training, 45(4), 226-235. 